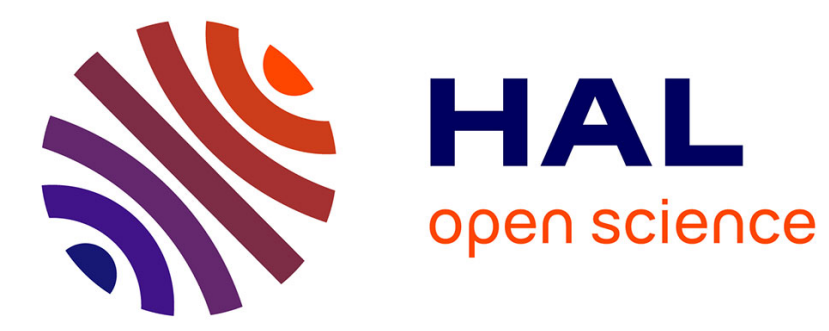

\title{
Degradation and biosynthesis of terpenoids by lactic acid bacteria isolated from cheese: first evidence
}

Simona Belviso, Manuela Giordano, Paola Dolci, Giuseppe Zeppa

\section{To cite this version:}

Simona Belviso, Manuela Giordano, Paola Dolci, Giuseppe Zeppa. Degradation and biosynthesis of terpenoids by lactic acid bacteria isolated from cheese: first evidence. Dairy Science \& Technology, 2011, 91 (2), pp.227-236. 10.1007/s13594-011-0003-z . hal-00874763

\section{HAL Id: hal-00874763 https://hal.science/hal-00874763}

Submitted on 18 Oct 2013

HAL is a multi-disciplinary open access archive for the deposit and dissemination of scientific research documents, whether they are published or not. The documents may come from teaching and research institutions in France or abroad, or from public or private research centers.
L'archive ouverte pluridisciplinaire HAL, est destinée au dépôt et à la diffusion de documents scientifiques de niveau recherche, publiés ou non, émanant des établissements d'enseignement et de recherche français ou étrangers, des laboratoires publics ou privés. 


\title{
Degradation and biosynthesis of terpenoids by lactic acid bacteria isolated from cheese: first evidence
}

\author{
Simona Belviso • Manuela Giordano • Paola Dolci • \\ Giuseppe Zeppa
}

Received: 14 January 2010 / Accepted: 2 July 2010 /

Published online: 24 March 2011

(C) INRA and Springer Science+Business Media B.V. 2011

\begin{abstract}
The aim of this study was to investigate whether lactic acid bacteria (LAB), isolated from cheese, were able to degrade terpenes. Five strains of LAB were grown on M17 and reconstituted skim milk in the presence of alpha-pinene, beta-myrcene, alphaterpineol, myrtenal, and alpha-campholenal. Cultures were incubated at $37{ }^{\circ} \mathrm{C}$ and samples collected at 6,24 , and $48 \mathrm{~h}$ for analysis by headspace-solid phase microextraction coupled with gas chromatography-mass spectrometry. The results showed that alphapinene, beta-myrcene, alpha-terpineol, and myrtenal degradation did not occur. Instead, all LAB cultures containing alpha-campholenal resulted in the almost complete disappearance of this substrate and the formation of a new monoterpenoid, tentatively identified as an isomer of borneol. In addition, the ability of the LAB strains to biosynthesize geraniol ex novo on both media was highlighted. This is the first evidence that LAB strains are able to modify and biosynthesize terpenoids. The results of this study could be used to play an important role in cheese traceability models based on the use of terpenes as plant biomarkers. In fact, their presence could be due not only to the animal feed but also to the LAB biomodification and biosynthetic activity.
\end{abstract}

\section{初步探讨源于干酪的乳酸菌对萜类化合物的降解和生物合成}

摘要 研究了分离于干酪的乳酸菌是否对萜类化合物具有降解作用。五株乳酸 菌分别接种在含有 $\alpha$-松萜、 $\beta$-月桂烯、 $\alpha$-松油醇、香桃木醛和 $\alpha$-campholenal的 M17 和还原脱脂乳培养基中, 在 $37^{\circ} \mathrm{C}$ 下培养, 分别在 $6 \mathrm{~h} 、 24 \mathrm{~h}$ 和 $48 \mathrm{~h}$ 取样 后采用顶空固相微萃取结合 GC-MS 进行分析。实验结果表明, $\alpha$-松萜、 $\beta$-月 桂烯、 $\alpha$-松油醇和香桃木醛没有发生降解。而乳酸菌可以使 $\alpha$-campholenal完 全降解为新的单萜类化合物, 初步鉴定萜类化合物为龙脑的异构体。此外在两 种培养基中乳酸菌都能够合成香叶醇。本文首次证明了乳酸菌对萜类化合物的 改性和生物合成 根据这一结果, 如果用萜类化合物作为植物的生物标记物, 将 对干酪的可追溯性起到非常重要的作用。事实上干酪中的萜类化合物不仅仅来 源于饲料中, 有可能来源于乳酸菌的生物改性作用和生物合成的代谢活动

S. Belviso $(\bowtie) \cdot$ M. Giordano $\cdot$ P. Dolci $\cdot$ G. Zeppa

Department of Exploitation and Protection of the Agricultural and Forestry Resources,

University of Turin, Grugliasco, (TO), Italy

e-mail: simona.belviso@unito.it 
Keywords Degradation $\cdot$ Biosynthesis $\cdot$ Terpenoids $\cdot$ Lactic acid bacteria

关键词 降解·生物合成·萜类化合物·乳酸菌

\section{Introduction}

Terpenes are secondary metabolites produced by higher plants, algae, and fungi. These compounds can play many biological roles (protection, attractants, allelochemicals, etc.), and they have demonstrated various properties such as antimicrobial, antifungal, antiparasitic, antiviral, anti-allergenic, anti-inflammatory, and chemotherapeutic; finally, their use as flavors and fragrances in food and cosmetics has been largely documented (Ajikumar et al. 2008). Therefore, an increasing interest in large-scale terpene production has arisen, and many studies have been carried out to improve biotechnological methods as "natural" processes to obtain pure enantiomers under mild reaction conditions (Serra et al. 2005). These studies contribute to the knowledge of a wide range of microorganisms able to perform a bioconversion on these molecules, and to the discovery that some biotransformations could have important effects on the distinctive aroma of some food products and beverages such as wine (De Carvalho and Da Fonseca 2006; Hernandez-Orte et al. 2009). Studies on the biodegradation of terpenes have mostly regarded yeasts (Carrau et al. 2005) and bacteria from soil (Madyastha et al. 1977; Chatterjee 2004), insects (Foss et al. 1998; Hylemon and Harder 1998), and rumen fluid (Broudiscou et al. 2007). Among lactic acid bacteria (LAB) selected from cheese, only a biosynthetic activity of terpenes has been reported for Lactobacillus acidophilus (Imhof et al. 1995). As secondary plant metabolites, terpenes could also be ingested by animals and then transferred into associated milk and cheeses (Coulon et al. 2004). This property was exploited by many authors in order to trace above all mountain dairy products (Coulon et al. 2004; Cornu et al. 2005; Favaro et al. 2005; Fernández García et al. 2008). Since LAB represent the main microflora of dairy products, the aim of this work was to investigate if some LAB strains, isolated from cheese, were able to degrade terpenes. For this study, monoterpenes such as alpha-pinene, beta-myrcene, alpha-terpineol, myrtenal, and alpha-campholenal were selected. Some of these compounds were also frequently found in a large variety of cheeses independently from the type or the geographic origin (De Noni and Battelli 2008).

\section{Materials and methods}

\subsection{LAB strains}

Five LAB strains, belonging to Lactococcus lactis subsp. lactis, Lactococcus lactis subsp. cremoris, Streptococcus thermophilus, Streptococcus macedonicus, and Lactobacillus paracasei, coming from the culture collection of the Department of Exploitation and Protection of the Agricultural and Forestry Resources, University of Turin (Italy) were used. These strains were isolated from Toma Piemontese PDO, 
an Italian cheese with protected designation of origin whose production is widespread particularly in the mountain areas of Piedmont (North West of Italy), and genetically identified (Fortina et al. 2003). Stock cultures were stored in $20 \%$ glycerol (Sigma, Milan, Italy) at $-20{ }^{\circ} \mathrm{C}$ until experiments started. Working cultures were maintained at $4{ }^{\circ} \mathrm{C}$ and were subcultured in M17 Broth (M17; Oxoid, Milan, Italy) before experimental use.

\subsection{Terpene compounds}

(+)-alpha-Pinene (purity higher than 99\%), beta-myrcene (purity higher than 95\%), (-)-borneol (purity higher than 99\%), and geraniol (purity higher than 99\%) were purchased from Fluka (Milan, Italy), alpha-terpineol (purity higher than 99\%) from Acros (Milan, Italy), (-)-myrtenal (purity higher than 97\%) and isoborneol (purity higher than 95\%) from Aldrich (Milan, Italy), and alpha-campholenal (purity higher than 85\%) from Chemos Group (Regenstauf, Germany).

\subsection{Culture conditions: $48 \mathrm{~h}$}

Two different culture media were used: M17 and 10\% (w/v) of reconstituted skim milk (RSM, Oxoid). Batch incubations were carried out dispensing $10 \mathrm{~mL}$ of each culture medium into $40-\mathrm{mL}$ tubes capped with a polytetrafluoroethylene/silicone septum (Supelco, Bellefonte, PA, USA) and properly sterilized. Prior to sterilization, a magnetic stir bar was added to the tubes. Cultures of each strain were taken at the end of the exponential phase of growth and inoculated at 2\% into M17 and RSM. Terpene solutions were obtained by dissolving each terpene in absolute ethanol at the concentration of $1,000 \mathrm{mg} \cdot \mathrm{L}^{-1}$ and separately added to each culture media at a final concentration of $2.5 \mathrm{mg} \cdot \mathrm{L}^{-1}$. The following blank solutions were also prepared: (1) tubes containing only sterile culture media, (2) tubes containing sterile media with terpenes, and (3) tubes containing sterile media inoculated with strains. Tubes were incubated under static conditions at $37^{\circ} \mathrm{C}$ for 2 days. The acidification curves of LAB were determined by monitoring culture $\mathrm{pH}$ with a MicropH $2002 \mathrm{pH}$ meter (Crison Instruments, Modena, Italy).

Each assay was carried out in triplicate. Samples were collected at 6, 24, and 48 hours of growth, cooled at room temperature, and analyzed by headspace solid phase microextraction (HS-SPME) coupled with gas chromatography-mass spectrometry (GC-MS).

\subsection{HS-SPME extraction}

A 2-cm (50/30 $\mu \mathrm{m}$ divinylbenzene/carboxen/polydimethylsiloxane) SPME fiber (Supelco) was used for the extraction of terpenes according to Zeppa et al. (2005). Briefly, samples were equilibrated at $53{ }^{\circ} \mathrm{C}$ for $10 \mathrm{~min}$ and extracted at the same temperature for $30 \mathrm{~min}$ under stirring. After the extraction, the fiber was introduced into the injector of a gas chromatograph coupled with a mass spectrometer (GC-MS) and maintained at $270{ }^{\circ} \mathrm{C}$ for 4 min for thermal desorption of terpenes. 


\subsection{GC-MS analysis}

GC-MS analyses were carried out on a Shimadzu GC-17A gas chromatograph equipped with a Shimadzu QP-5000 quadrupole mass spectrometer detector (Shimadzu Corporation, Kyoto, Japan). Separation was achieved on a DB-WAX capillary column $(30 \mathrm{~m} \times 0.25 \mathrm{~mm}$ i.d., $0.25 \mu \mathrm{m}$ film thickness; J\&W Scientific Inc., Folsom, CA, USA). The oven temperature was programmed at $35^{\circ} \mathrm{C}$ held for $5 \mathrm{~min}$, increased to $135^{\circ} \mathrm{C}$ at $2{ }^{\circ} \mathrm{C} \mathrm{min}^{-1}\left(1 \mathrm{~min}\right.$ hold), then increased to $210{ }^{\circ} \mathrm{C}$ at $15^{\circ} \mathrm{C} \mathrm{min}{ }^{-1}$ and held at the final temperature for $5 \mathrm{~min}$. Injector temperature was $270{ }^{\circ} \mathrm{C}$ and injection mode splitless. Helium was used as carrier gas at $1.0 \mathrm{~mL} \mathrm{~min}{ }^{-1}$. The detector operated in electron impact ionization mode at $70 \mathrm{eV}$ with the GC-MS interface at $230{ }^{\circ} \mathrm{C}$, and $\mathrm{m} / \mathrm{z}$ scan range of 33 to 300 was collected. Compound identification was achieved by comparing mass spectra and linear retention indices (LRI) with those of authentic standards and/or with those recorded in NIST12, NIST62 (National Institute of Standards and Technology, Gaithersburg MD, USA), and other published mass spectral database (Adams 2001). LRI were calculated by linear interpolation relative to retention times of $\mathrm{C}_{5}-\mathrm{C}_{25} n$-alkanes as external references.

For each terpene, the area (arbitrary unit) of the most abundant or characteristic ion $m / z$ was extracted from the total ion current (TIC) and integrated with a Class-5000 Data Station ver. 2.0 software (Shimadzu Corporation).

\subsection{Alpha-campholenal stability assay}

Alpha-campholenal was added to $10 \mathrm{~mL}$ of sterile M17 and RSM media as solution in absolute ethanol at $1,000 \mathrm{mg} \cdot \mathrm{L}^{-1}$ to obtain a final concentration of $2.5 \mathrm{mg} \cdot \mathrm{L}^{-1}$, as previously described; then, media were acidified at $\mathrm{pH} 4$ and 5 with acetic acid, and extracted by HS-SPME after 6, 24, and $48 \mathrm{~h}$ of incubation at $37^{\circ} \mathrm{C}$. Analyses were carried out on GC-MS as previously described.

\subsection{Geraniol quantification}

Geraniol was quantified, in each growth medium, using an external standard calibration. Analyte concentration was determined by integrating the area of the characteristic ion peak of the geraniol $(m / z=69)$ extracted from TIC. The detection limit (LOD) and the quantification limit (LOQ) were estimated using the signal-to-noise method. The signal-to-noise ratios used for LOD and LOQ were 3 and 10, respectively. The concentration range used for the calculation of the calibration curve on M17 was 1.9$5.0 \mu \mathrm{g} \cdot \mathrm{L}^{-1}$. In this interval, the calibration curve was linear with $R^{2}=0.9911$. LOD was $0.7 \mu \mathrm{g} \cdot \mathrm{L}^{-1}$ and LOQ $1.9 \mu \mathrm{g} \cdot \mathrm{L}^{-1}$; on RSM LOD was $2.0 \mu \mathrm{g} \cdot \mathrm{L}^{-1}$ and LOQ $7.5 \mu \mathrm{g} \cdot \mathrm{L}^{-1}$.

\section{Results and discussion}

3.1 Degradation of alpha-campholenal and formation of new terpenoidic metabolites

The disappearance of terpenes, in all tubes, was monitored by plotting the terpene peak areas as a function of time. Among the compounds assayed, only alpha- 
campholenal underwent degradation, in presence of LAB cultures. Moreover, in these samples, the alpha-campholenal disappearance was accompanied by the appearance of a newly found monoterpenoid [MS—95(100), 105(13), 121(16), 136 (3), 139(6); $\left.\mathrm{LRI}_{\text {DB-WAX }}=1,784\right]$. In Figs. 1 and 2, the alpha-campholenal peak area ( $y$-axis on the left) and the monoterpenoid peak area ( $y$-axis on the right) were plotted as a function of the incubation time ( $x$-axis). These figures showed that all

Lactococcus lactis subsp. lactis

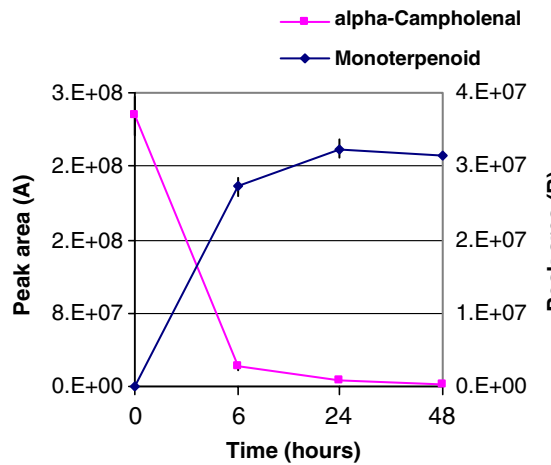

Streptococcus macedonicus

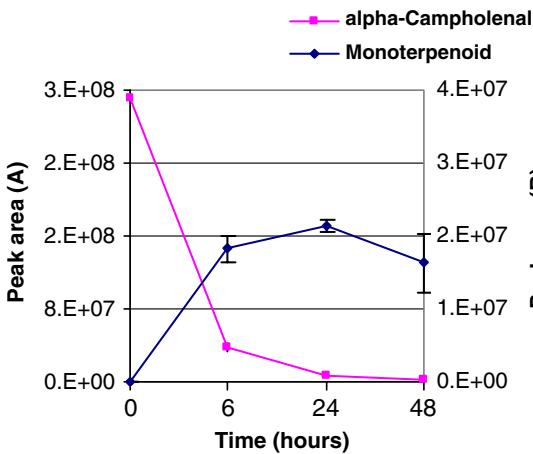

Lactococcus lactis subsp. cremoris

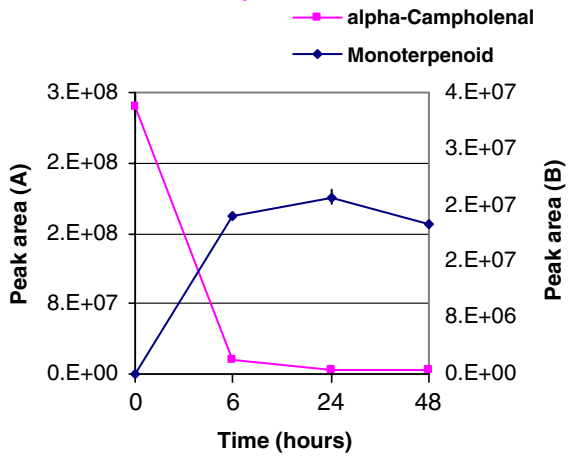

Streptococcus thermophilus
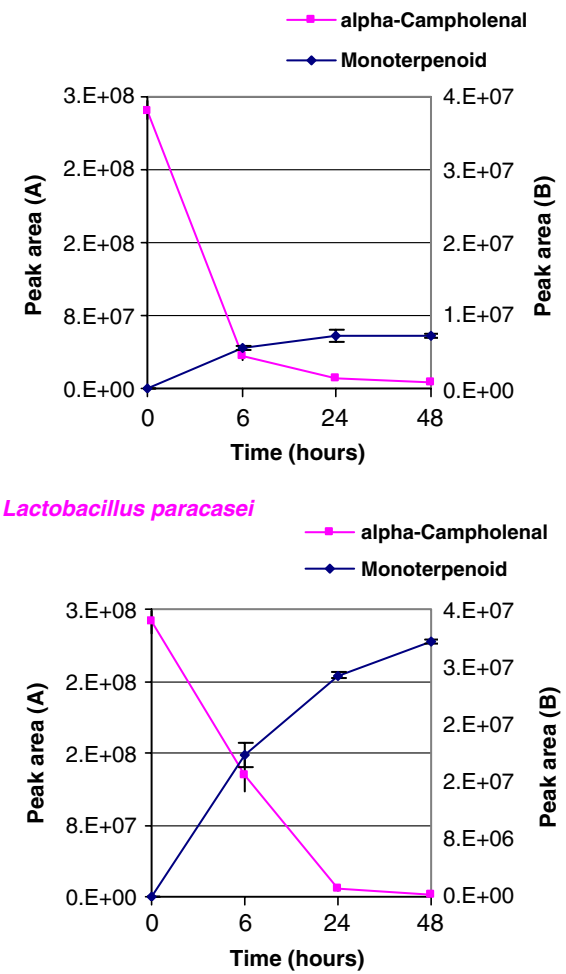

Fig. 1 Alpha-campholenal and monoterpenoid (tentatively identified as borneol isomer) peak areas (arbitrary unit) \pm standard deviations in function of incubation time (hours) on M17 growth medium. a Alpha-campholenal, b monoterpenoid 

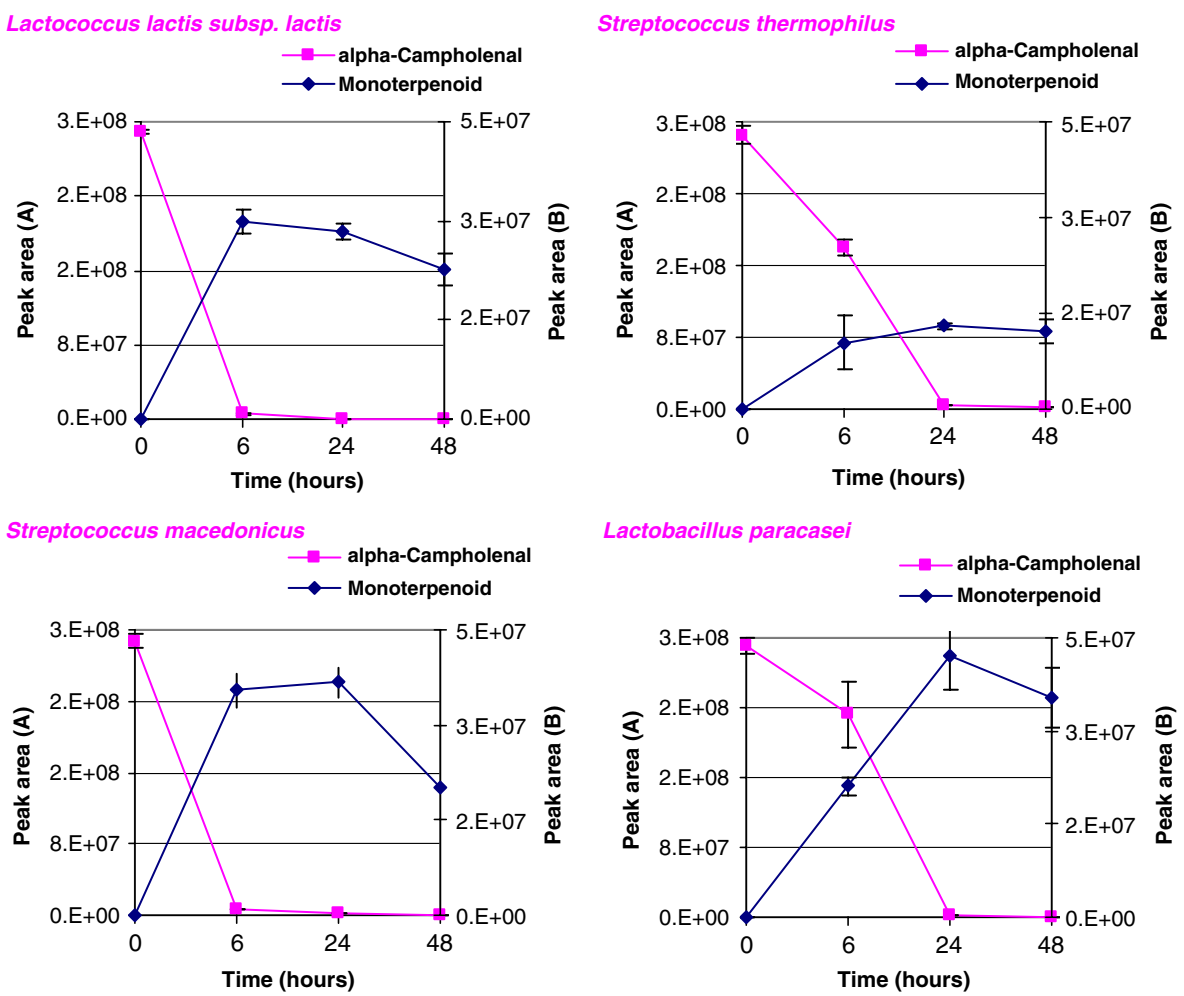

Lactococcus lactis subsp. cremoris

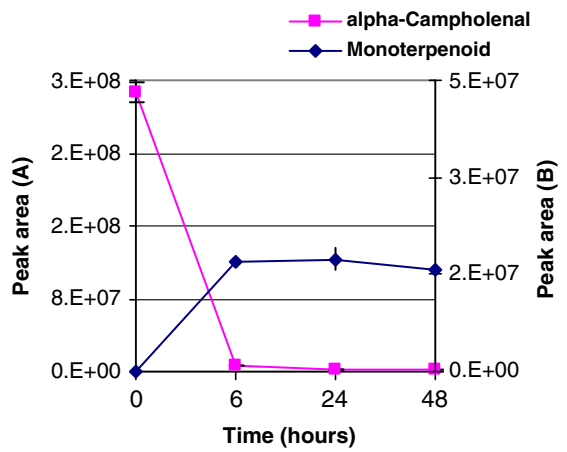

Fig. 2 Alpha-campholenal and monoterpenoid (tentatively identified as borneol isomer) peak areas (arbitrary unit) \pm standard deviations in function of incubation time (hours) on reconstituted skim milk growth medium. a Alpha-campholenal, b monoterpenoid

strains were able to perform the degradation of alpha-campholenal. This compound was mostly degraded during the first $6 \mathrm{~h}$ of growth, except in the L. paracasei RSM culture where the degradation seemed to need more time to be performed (Fig. 2). Then, the alpha-campholenal decreased more slowly and, at $48 \mathrm{~h}$ of growth, it almost completely disappeared (Figs. 1 and 2). Generally, the new monoterpenoid peak area increased faster during the first $6 \mathrm{~h}$ of growth, which is in agreement with the more rapid disappearance of the alpha-campholenal in the same time range. 
Then, the monoterpenoid peak area increased until $24 \mathrm{~h}$ less rapidly, and finally, it remained constant. However, for L. paracasei cultures and S. macedonicus RSM culture, different trends were observed. In fact, in L. paracasei cultures, the formation of the new monoterpenoid was less rapid during the early growth stages, and it reached the maximum peak area at $24 \mathrm{~h}$ on RSM and at $48 \mathrm{~h}$ on M17 (Figs. 1 and 2). Instead, in S. macedonicus RSM culture, an unexpected decrease of the monoterpenoid was observed (Fig. 2). The most active strains in the monoterpenoid production, on both M17 and RSM, seemed to be L. lactis and L. paracasei (Figs. 1 and 2). On RSM, also S. macedonicus exhibited a high monoterpenoid peak area (Fig. 2). On S. thermophilus M17 and RSM cultures and on L. cremoris RSM culture, the lowest monoterpenoid peak areas were found. Besides the monoterpenoid, other minor compounds were found on the media inoculated with LAB strains (Table 1). Some of these molecules were probably not found on RSM as their abundance was too low to be detected. Most of them were unidentified terpenic compounds. It may be supposed that they can be obtained also from the degradation of alpha-campholenal.

Analyses of blank solutions assessed that the incubation conditions and the LAB acidification activity did not influence the alpha-campholenal disappearance. In addition, the terpenoids were not detected in cell-free tubes containing the growth media. Thus, LAB cells were responsible for both the degradation of alphacampholenal and the appearance of the new terpenoidic metabolites. LAB biomodifications on alpha-campholenal are still unknown. Only a supposed mechanism can be proposed. Probably, LAB carried out the reduction of the aldehyde group of the alpha-campholenal to the hydroxyl group; then, a rearrangement of the molecule could be responsible for the formation of the new monoterpenoid. The reduction step could be possible as it has been already observed for wine-associated lactic acid bacteria (Swiegers et al. 2005; Bloem et al. 2007). Also, rearrangements of the carbon skeleton are typical of the chemistry of bicyclic terpenes. However, no experimental evidence exists now to support this hypothesis.

Table 1 Minor biodegradation products detected on M17 and RSM media during LAB growth

\begin{tabular}{llr}
\hline No. & Compound & LRI \\
\hline 1 & Carvone oxide & 1,681 \\
2 & Isoborneol & 1,721 \\
3 & Isomer 1a; MS: 41(100), 67(65), 93(45), 81(24), 111(18), 121(17), 136(6) & 1,822 \\
4 & Isomer 1b; MS: 41(100), 67(70), 93(51), 81(23), 111(13), 121(13), 136 (11) & 1,826 \\
5 & Isomer 2a; MS: 108(100), 93(43), 67(23), 81(22), 196(4) & 1,924 \\
6 & Isomer 2b; MS: 108(100), 93(44), 67(23), 81(22), 196(4) & 1,926 \\
7 & Isomer 3a; MS: 43(100), 107(85), 95(41), 67(38), 79(29), 196(8) & 1,930 \\
8 & Isomer 3b; MS: 43(100), 107(62), 95(36), 67(30), 79(22), 196(7) & 1,938 \\
9 & Isomer 4a; MS: 121(100), 108(97), 81(94), 137(77), 93(75), 136(45) & 1,992 \\
10 & Isomer 4b; MS: 121(100), 108(82), 81(71), 137(63), 93(59), 136(51) & 2,002
\end{tabular}




\subsection{Tentative identification of the monoterpenoid}

This compound had the molecular ion at $154 \mathrm{~m} / \mathrm{z}$, which corresponds to the molecular weight, and the molecular formula $\mathrm{C}_{10} \mathrm{H}_{18} \mathrm{O}$. The comparison of the mass spectrum with those recorded in the spectral libraries resulted in the identification of the monoterpenoid as borneol or isoborneol, which had the same molecular ion and very similar fragmentation patterns (Fig. 3). However, LRI values, calculated for borneol $\left(\mathrm{LRI}_{\mathrm{DB}-\mathrm{WAX}}=1,687\right)$ and isoborneol $\left(\mathrm{LRI}_{\mathrm{DB}-\mathrm{WAX}}=1,654\right)$, after the injection of the authentic standards, were different from that calculated for the unknown compound $\left(\mathrm{LRI}_{\mathrm{DB}-\mathrm{WAX}}=1,784\right)$. Thus, the new monoterpenoid was tentatively identified as another isomer of borneol.

\subsection{Biosynthesis of geraniol}

The chromatographic profiles of M17 and RSM inoculated with LAB strains, without the addition of terpenes, showed the presence of the geraniol $\left(\mathrm{LRI}_{\mathrm{DB}-\mathrm{WAX}}=1,841\right)$, indicating that these bacteria are able to biosynthesize this terpenoid ex novo.

On M17, S. macedonicus, S. thermophilus, and L. cremoris biosynthesized geraniol quantity below the LOQ, while for L. lactis the biosynthesis gained its maximum at $24 \mathrm{~h}\left(2.0 \pm 0.08 \mu \mathrm{g} \cdot \mathrm{L}^{-1}\right)$ and was not quantifiable $(<\mathrm{LOQ})$ at 6 and $48 \mathrm{~h}$. The highest geraniol biosynthesis was observed for L. paracasei. In fact, the geraniol yield increased to $4.02 \pm 0.05 \mu \mathrm{g} \cdot \mathrm{L}^{-1}$ at $24 \mathrm{~h}$ and to $4.36 \pm 0.03 \mu \mathrm{g} \cdot \mathrm{L}^{-1}$ at $48 \mathrm{~h}$. On RSM, geraniol production was below the LOQ for all strains.
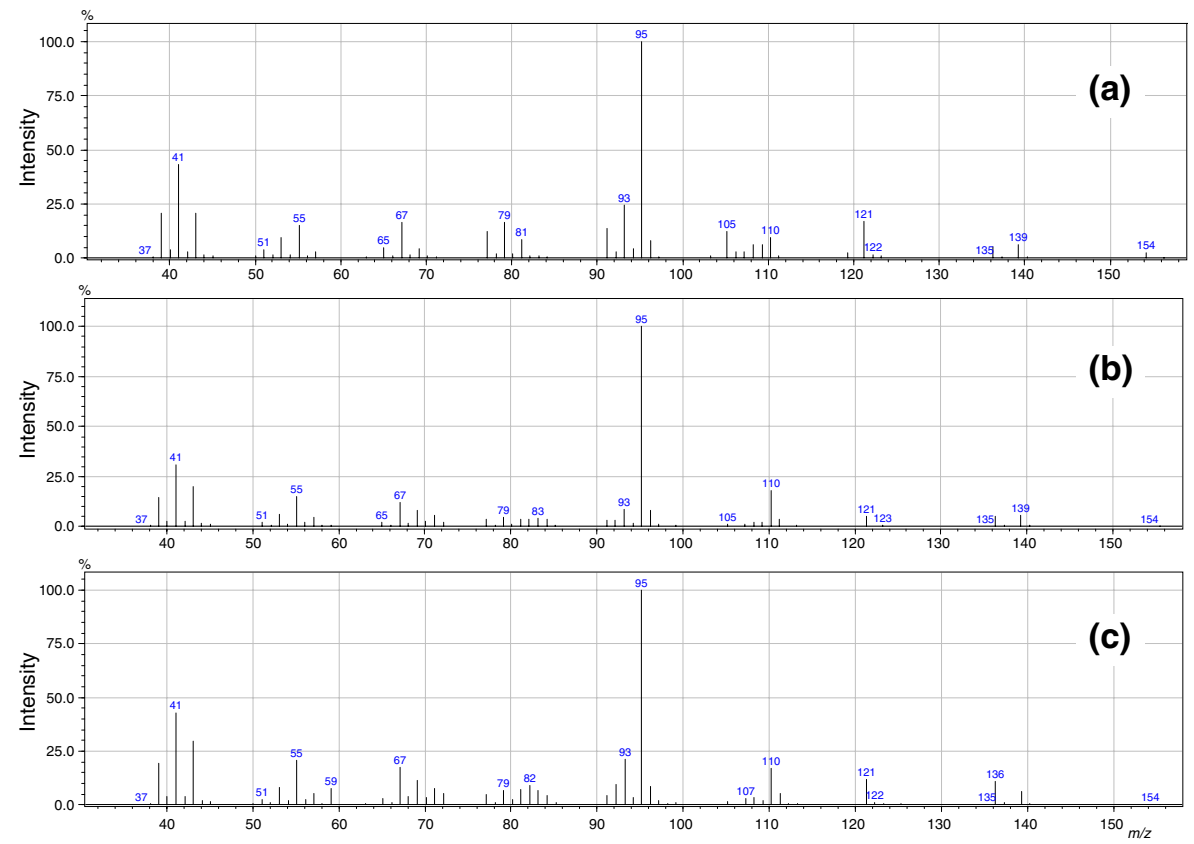

Fig. 3 Comparison between the mass spectra of the new monoterpenoid (tentatively identified as borneol isomer) (a) and those of the authentic standards, borneol (b) and isoborneol (c) 


\section{Conclusions}

The ability of LAB strains, isolated from cheese, to degrade, modify, and biosynthesize monoterpenes was evidenced for the first time, to our knowledge, in this study, highlighting novel metabolic capabilities for these bacteria. Besides, these results should be taken into account in the definition of cheese traceability models, especially those based on the research of plant biomarkers, as are terpenes. In fact, even though it has been shown in this study that some of the most frequently occurring monoterpenes were not degraded by LAB, the presence of these kinds of molecules, in dairy products, could be due not only to the animal feed but also to the LAB biotransformation and biosynthetic activity.

\section{References}

Adams RP (2001) Identification of essential oil components by gas chromatography/quadrupole mass spectroscopy. Allured, Carol Stream

Ajikumar PK, Tyo K, Carlsen S, Mucha O, Phon TH, Stephanopoulos G (2008) Terpenoids: opportunities for biosynthesis of natural product drugs using engineered microorganisms. Mol Pharm 5:167-190

Bloem A, Bertrand A, Lonvaud-Funel A, de Revel G (2007) Vanillin production from simple phenols by wine-associated lactic acid bacteria. Lett Appl Microbiol 44:62-67

Broudiscou LP, Cornu A, Rouzeau A (2007) In vitro degradation of 10 mono- and sesquiterpenes of plant origin by caprine rumen micro-organisms. J Sci Food Agric 87:1653-1658

Carrau FM, Medina K, Boido E, Farina L, Gaggero C, Dellacassa E, Versini G, Henschke PA (2005) De novo synthesis of monoterpenes by Saccharomyces cerevisiae wine yeast. FEMS Microbiol Lett 243:107-115

Chatterjee T (2004) Biotransformation of geraniol by Rhodococcus sp. strain GR3. Biotechnol Appl Biochem 39:303-306

Cornu A, Kondjoyan N, Martin B, Verdier-Metz I, Pradel P, Berdarguè JL, Coulon JB (2005) Terpene profiles in Cantal and Saint-Nectaire-type cheese made from raw or pasteurised milk. J Agric Food Chem 85:2040-2046

Coulon JB, Delacroix-Buchet A, Martin B, Pirisi A (2004) Relationship between ruminant management and sensory characteristics of cheeses: a review. Lait 84:221-241

De Carvalho CCCR, Da Fonseca MMR (2006) Biotransformation of terpenes. Biotechnol Adv 24:134-142

De Noni I, Battelli G (2008) Terpenes and fatty acid profiles of milk fat and "Bitto" cheese as affected by transhumance of cows on different mountain pastures. Food Chem 109:299-399

Favaro G, Magno A, Boaretto A, Bailoni L, Mantovani R (2005) Traceability of Asiago mountain cheese: a rapid, low-cost analytical procedure for its identification based on solid-phase microextraction. J Dairy Sci 88:3426-3434

Fernández García E, Imhof M, Schlichtherle-Cerny H, Bosset JO, Nuñez M (2008) Terpenoids and benzenoids in La Serena cheese made at different seasons of the year with a Cynara cardunculus extract as coagulant. Int Dairy J 18:147-157

Fortina MG, Ricci G, Acquati A, Zeppa G, Gandini A, Manachini PL (2003) Genetic characterization of some lactic acid bacteria occurring in an artisanal protected denomination origin (PDO) Italian cheese, the Toma Piemontese. Food Microbiol 20:397-404

Foss S, Heyen U, Harder J (1998) Alcaligenes defragrans sp. nov., description of four strains isolated on alkenoic monoterpenes ((+)-menthene, alpha-pinene, 2-carene, and alpha-phellandrene) and nitrate. Syst Appl Microbiol 21:237-244

Hernandez-Orte P, Cersosimo M, Loscos N, Cacho J, Garcia-Moruno E, Ferreira V (2009) Aroma development from non-floral grape precursors by wine lactic acid bacteria. Food Res Int 42:773-781

Hylemon PB, Harder J (1998) Biotransformation of monoterpenes, bile acids, and other isoprenoids in anaerobic ecosystems. FEMS Microbiol Rev 22:475-488

Imhof R, Glatti H, Bosset JO (1995) Volatile organic compounds produced by thermophilic and mesophilic single strain dairy starter culture. Lebensm Wiss Technol 28:78-96 
Madyastha KM, Bhattacharyya PK, Vaidynathan CS (1977) Metabolism of a monoterpene alcohol, linalool, by a soil pseudomonad. Can J Microbiol 23:230-239

Serra S, Fuganti C, Brenna E (2005) Biocatalytic preparation of natural flavours and fragrances. Trends Biotechnol 23:193-198

Swiegers JH, Bartowsky EJ, Henschke PA, Pretorius IS (2005) Yeast and bacterial modulation of wine aroma and flavour. Aust J Grape Wine Res 11:139-173

Zeppa G, Giordano M, Bertolino M, Gerbi V (2005) Application of artificial neural network on mono- and sesquiterpenes compounds determined by headspace solid-phase microextraction gas chromatographymass spectrometry for the Piedmont ricotta cheese traceability. J Chromatogr A 1071:247-253 